\title{
A CONTRIBUIÇÃO DE PIAGET E A EXPERIÊNCIA PRÁTICA: UM ESTUDO DE CASO SOBRE A FORMAÇÃO DO PROFES- SOR DE EDUCAÇÃO INFANTIL
}

\author{
Tania Márcia da Cunha Rodrigues 1 \\ Maria Luiza Rheingantz Becker ${ }^{2}$
}

\section{Resumo}

Este artigo questiona se um professor de educação infantil com anos de prática sabe diferenciar algumas características próprias do pensamento da criança, presentes na obra de Piaget, mesmo que não tenha lido, ouvido ou conhecido qualquer referência à Epistemologia Genética. Assume-se aqui a relevância da teoria piagetiana para a educação infantil, na atualidade. Questiona-se a relação teoria e prática na formação de professores de Educação Infantil. A partir dessa perspectiva, apresenta-se um estudo de caso com uma professora de crianças de 0 a 5 anos, realizado em maio de 2018, como estudo preliminar de uma dissertação de mestrado. Os resultados mostram que algumas das observações sobre as crianças, relatadas pela professora, são coerentes com as contribuições de Piaget no estudo da mentalidade infantil. A metodologia utilizada, baseada em entrevista semiestruturada inspirada no método clínico de Jean Piaget foi considerada adequada aos objetivos da investigação.

Palavras-chave: Epistemologia Genética; formação de professores de educação infantil; mentalidade infantil.

\footnotetext{
1 Licenciada em Pedagogia (UFSM-RS), Psicopedagoga Clínica e Institucional (UNILASALLE-RS), Especialista em Educação Especial e Processos Inclusivos (UFRGS-RS) e em Gestão de Processos Educacionais (UFRN-RN). Mestranda em Educação (UFRGS-RS). E-mail: tania.cunha10@gmail.com

2 Licenciada em Psicologia pela Pontifícia Universidade Católica do Rio Grande do Sul, com doutorado em Educação pela Universidade Federal do Rio Grande do Sul. Atualmente é professora associada da Universidade Federal do Rio Grande do Sul. Atua nos cursos de licenciatura, na graduação, e na Linha de Pesquisa: Psicopedagogia, sistemas de ensino e aprendizagem e educação em saúde, do PPGEdu. Email: beckermarialuiza@gmail.com
}

Volume 10 Número 2 - Ago-Dez/2018

www.marilia.unesp.br/scheme 


\title{
THE CONTRIBUTION OF PIAGET AND PRACTICAL EXPERI- ENCE: A CASE STUDY ON THE FORMATION OF THE TEACHER OF EARLY CHILDHOOD EDUCATION
}

\begin{abstract}
This article questions whether a preschool teacher with years of practice can identify certain thought patterns in children which are present in Jean Piaget's work even if this teacher has never read, heard or known anything about Genetic Epistemology. Based on the current relevance of Piaget's theory for childhood education, the article analyzes the relationship between theory and practice in the professional development of preschool teachers. It presents a case study of a teacher who works with children aged 0 to 5 years, which was carried out in May 2018 as a pilot study for a master's thesis. The method used and deemed suitable for the purposes of this research was a semi-structured interview based on Jean Piaget's clinical method. The results show that some observations made by the teacher about the children are in line with Piaget's contributions to the study of child development.
\end{abstract}

Keywords: Genetic Epistemology, professional development of preschool teachers, child development.

\section{Introdução}

Estudos recentes mostram que a educação infantil voltada para o desenvolvimento integral da criança tem ganhado cada vez mais atenção. Questões anteriormente deixadas de lado, como a ludicidade e os aspectos advindos da própria criança, passaram a ser consideradas importantes para a construção de seu conhecimento.

Pode parecer estranho, para alguns leitores, que se busque referencial fundamentado na teoria de Jean Piaget para pensar a formação de professores de educação infantil. É de notório conhecimento que esse autor não desen- 


\section{Sthòme \\ Revista Eletrônica de Psicologia e Epistemologia Genéticas}

volveu sua teoria com a preocupação de que seu trabalho servisse como base para a Educação. Entretanto, questiona-se se a educação infantil pode acontecer de forma efetiva sem que o educador conheça a teoria de Piaget, compreenda sua relevância e conheça o quanto sua ciência epistemológica está ligada a aspectos de formação de professores e do trabalho pedagógico com as crianças. Toda prática que resulta ora em êxitos, ora em fracassos, traz em si uma teoria. Sem a consciência dessa teoria, a razão dos êxitos e fracassos pode não ser compreendida pelo educador.

Este estudo de caso investiga se um professor de educação infantil que ainda não possui formação específica completa na área de desenvolvimento da criança é capaz de desenvolver um trabalho intuitivo eficiente em sala de aula com crianças entre 0 a 5 anos - faixa etária definida pela Lei n.11.114, de 16 de maio de 2005, como a da primeira etapa da educação básica. (BRASIL, 2005).

Acredita-se que o cientista suíço Jean Piaget (1896-1980), mesmo sem ser pedagogo, foi e perdura como um dos pensadores mais influentes na Educação. Sua teoria continua instigando reflexões profundas sobre a construção do conhecimento e a forma como este vem sendo desenvolvido no âmbito da educação infantil.

\section{O conhecimento inicial do professor ou da professora de educação infantil}

Este artigo questiona se um professor de educação infantil com anos de prática sabe diferenciar algumas características próprias do sujeito universal presentes na obra de Piaget mesmo que não tenha lido, ouvido ou conhecido qualquer referência à teoria piagetiana. Reflete-se sobre a amplitude dessa formação do professor de educação infantil, considerando que, mesmo antes de uma formação específica sobre o desenvolvimento da criança, há casos em que ele pode desempenhar sua função de maneira efetiva. É provável que, a partir

Volume 10 Número 2 - Ago-Dez/2018

www.marilia.unesp.br/scheme 


\section{Şchème \\ Revista Eletrônica de Psicologia e Epistemologia Genéticas}

de sua prática e convivência com as crianças, passe a observar e compreender as diferenças existentes entre elas, as transformações nas suas condutas, e relacioná-las com as diferentes etapas da vida. Piaget $(1949 / 1998)^{3}$ ao fazer uma analogia entre as relações existentes entre a fisiologia e a psicologia e entre a medicina e a educação. O autor, afirma que:

A pedagogia como a medicina: uma arte, mas que se apoia - ou deveria se apoiar - sobre conhecimentos científicos precisos. As aptidões de um bom médico [...] são sem dúvida individuais e quase inatas: não se aprendem e são, no máximo, possíveis de desenvolvimento. Mas, de nada serviria a um clínico possuí-las se não tivesse se iniciado, durante anos, na anatomia, na fisiologia, na patologia e na clínica. Da mesma maneira, nasce-se pedagogo: ninguém se torna pedagogo e as mais belas lições de metodologia não fornecem o segredo do contato com as crianças a um futuro professor que não gosta delas. Mas, ainda que fossemos educadores até a medula dos ossos, é preciso conhecer não apenas as matérias que ensinamos, mas também a própria criança, a quem nos dirigimos, ou o adolescente: em suma o aluno como ser vivo, que reage, se transforma e se desenvolve mentalmente segundo leis tão complexas como as de seu organismo físico. (PIAGET, 1949/ 1998, p. 181).

O objetivo deste estudo não é, de modo algum, defender a não qualificação do professor de educação infantil. Pelo contrário: o objetivo é a ampliação do olhar sobre a formação inicial desse educador, considerando-o como um profissional que constrói seu pensamento ao longo de suas trocas com o meio e suas experiências práticas com crianças pequenas. Essas construções acarretarão práticas educacionais diferentes das de um profissional que não teve esse contato com crianças. Conforme Piaget (1959/19964), existe, no sujeito de aprendizagem, uma seleção natural de condutas em que algumas novidades são assimiladas, gerando acomodação das estruturas mentais, e outras não.

\footnotetext{
3 Sobre a Pedagogia: textos inéditos: Esta publicação trata de textos inéditos durante a vida de Piaget, organizados em 1998 por Sílvia Parrat-Dayan e Anastásia Tryphon. As organizadoras escrevem a Introdução do livro.

4 Para esclarecer o leitor sobre a obra original citada, este artigo fará sempre referência às duas datas: original/obra lida.
}

Volume 10 Número 2 - Ago-Dez/2018

www.marilia.unesp.br/scheme 
Ao refletir sobre sua prática e relacioná-la com a teoria piagetiana e/ou outras teorias, o profissional pode atingir um nível diferenciado de compreensão e interpretação. A construção de conhecimentos práticos e as trocas anteriores o qualificam como possuidor de um olhar mais amplo, que o especializará de maneira mais eficiente.

Nessa perspectiva, este estudo reconhece que a formação inicial do professor de educação infantil pode começar antes dos cursos específicos (magistério, auxiliar de educação infantil ou atendente de creche, cursos de extensão sobre o tema, pedagogia ou especializações). O convívio e as práticas educacionais com crianças fazem parte da formação profissional contínua; muitos professores que não possuem formação teórica podem, ainda assim, em suas práticas educacionais, construir conhecimentos fundamentais relacionados aos pressupostos trazidos por Jean Piaget. Esses professores orientam-se pela observação dos resultados de suas ações. Em síntese, conclui-se que esses profissionais se tornam capazes de incorporar observações análogas às de Piaget a seus métodos pedagógicos mesmo que não consigam expor o princípio teórico utilizado.

A visão de mundo da criança pelo olhar do professor ou da professora de educação infantil.

A ideia que se construiu durante este estudo de caso é a de que o professor de educação infantil que não possui formação específica na área de desenvolvimento da criança ou que não possui formação de terceiro grau apresenta, em suas práticas, muitas intuições e compreensões sobre as características e o desenvolvimento da mentalidade infantil. 
No caso a ser apresentado, a entrevistada faz relatos e algumas generalizações sobre muitas de suas práticas que remetem à teoria de Piaget. É possível observar isso nos trechos seguintes de fala da entrevistada:

“[...] é sempre uma descoberta, sempre algo novo [...] tu observas a criança e tu vês nitidamente que elas têm momentos bem diferentes [...] e, nesses momentos, se demonstra o que todas acabam passando naquela idade."

"[...] Cada um tem seu tempo! Uns demoram mais para passar de uma fase da vida para outra. Mas, aí, [...] de repente, ela tem um click...".

Ou seja, essa professora de educação infantil, mesmo sem referir a teoria piagetiana, tem uma forma própria de considerar a mentalidade infantil. Este é o foco escolhido para este estudo de caso.

\section{Mentalidade infantil 5}

Piaget inicia sua teoria com o intuito de provar sua hipótese de que a mentalidade infantil se desenvolve a partir das construções de estruturas, as quais as crianças manifestam através do discurso verbalizado. Ele passou a ter grande interesse pela linguagem e representação e pelo julgamento moral das crianças, mas pensava de maneira clássica, e as perguntas que fazia para as crianças conservavam uma forma verbalizada e conceitual. O autor sugeriu que "o pensamento da criança é intermediário entre o pensamento autístico e o pensamento lógico do adulto, mostra-nos uma perspectiva que possibilita a interpretação do seu comportamento". (PIAGET, 1923/1993, p.11).

\footnotetext{
5 A expressão mentalidade infantil remete ao primeiro período da obra de Piaget conforme Montangero. J e Maurice-Naville. D, (1998), p.23. Ela foi usada por Claparède no prefácio de Linguagem e Pensamento da Criança (1923/1993) e aparece também nos estudos sobre a recepção da obra de Piaget, entre pedagogos dos anos 1920-1930, de Parrat-Dayan (Schème, vol I, no 2 - Jul-Dez/2008). Posteriormente, o termo vai sendo substituído por pensamento da criança.
}

Volume 10 Número 2 - Ago-Dez/2018

www.marilia.unesp.br/scheme 
Piaget (1923/1993) traz a ideia de uma inteligência prática e argumenta que a criança, ao nascer, possui um "aparato" cognitivo que inicialmente corresponde a ações e percepções sensoriais:

[...] o espírito da criança é tecido simultaneamente em dois planos diferentes, de certo modo superpostos um ao outro. $\mathrm{O}$ trabalho operado no plano interior é, nos primeiros anos, muito mais importante. É obra da própria criança, que atrai para si e cristaliza ao redor das suas necessidades tudo o que é capaz de satisfazê-la. É o plano da subjetividade, dos desejos, da brincadeira, [...]. O plano superior, é pelo contrário, edificado pouco a pouco pelo meio social cuja pressão impõe-se cada vez mais à criança. É o plano da objetividade, da linguagem, dos conceitos lógicos, em resumo, da realidade. (PIAGET, 1923/1993, p. $11)$.

Nessa perspectiva, a operação mental do bebê consiste em relações inobserváveis, construídas a partir das relações com o meio. Conforme afirma Claparède (In: PIAGET; 1923/1993, p. 12): “Enquanto se fazia do problema de mentalidade infantil um problema de quantidade, Piaget tornou-o um problema de qualidade". Ele afirma que Piaget trouxe uma nova forma de compreensão da criança devido "[...] ao fato de referir-se a outra espécie de pensamento, o pensamento autístico, ou simbólico, que o adulto há muito ultrapassou ou recalcou". (CLAPARÈDE. In: PIAGET; 1923/1993, p. 12).

No final do período sensório motor, iniciam-se as representações mentais por meio de imitações e experiências sensoriais. Para Piaget, a criança, ao se exercitar e se reorganizar, adapta-se aos objetos externos, elaborando, assim, sua atividade de pensar o mundo - o qual ela irá representar, posteriormente, por meio de jogos, de brincadeiras, da linguagem, etc. Ao observar e ouvir crianças entre dois e sete anos, Piaget compreendeu que elas têm dificuldades para compreender a reversibilidade nas relações que estabelecem. Por ainda estarem suscetíveis a certas configurações perceptivas, as crianças não conseguem compreender a diferença entre as transformações reais e as aparen-

Volume 10 Número 2 - Ago-Dez/2018 www.marilia.unesp.br/scheme 


\section{Sthòme \\ Revista Eletrônica de Psicologia e Epistemologia Genéticas}

tes. Nessa fase, as estruturas mentais são amplamente livres, intuitivas e altamente imaginativas.

O autor afirma que, durante esse período, a mentalidade infantil se distingue por dois subestádios. O pensamento intuitivo (a partir dos quatro anos) é um pensamento ligado às suas próprias percepções e às aparências das situações, no qual a criança consegue resolver alguns problemas, mas está sujeita às configurações perceptivas e, portanto, seu pensamento é irreversível. O pensamento pré-conceitual se caracteriza por uma forma de pensamento mágico em que a criança acredita que seus desejos se tornam realidade. Nesse subestádio, as peculiaridades do pensamento da criança são as seguintes: o animismo, que é a atribuição de características humanas a seres inanimados; o realismo, em que a realidade é construída pela criança; o finalismo, que se relaciona com a causalidade, no qual a criança olha o mundo e tenta explicar o que vê; o artificialismo, que é a explicação dada sobre os fenômenos naturais como se fossem produzidos pelos seres humanos para lhes servir; e, por fim, o egocentrismo, em que a criança faz referência a tudo o que acontece conforme seus sentimentos ou ações.

Para Piaget, essa fase é importantíssima para a criança, pois ela se socializa e aprende de maneira rápida através do desenvolvimento de sua linguagem e comunicação. Ele afirma que a origem do pensamento da criança decorre das modificações da ação da criança em sua interação com o meio, o que resulta em uma grande transformação da inteligência. (DONGO MONTOYA et al., 2011, p. 222). A partir desse processo, o que antes era apenas uma inteligência prática ou sensório-motora torna-se um pensamento propriamente dito. No entanto, a criança ainda não consegue reverter as ações que realizou no início para comprovar o seu raciocínio. Para dar resposta a um problema, considera so-

Volume 10 Número 2 - Ago-Dez/2018 www.marilia.unesp.br/scheme 
mente um aspecto de cada vez, característica pontual de centração do pensamento. No período pré-operatório, ela demonstra representação de ações, ainda que continue com pouca maleabilidade de seu pensamento, o que, por sua vez, a impede de compreender a reversibilidade dessas ações.

Foi a partir dessas ideias trazidas pela teoria piagetiana que a criança passou a ser vista de uma maneira diferente pelo mundo científico e cultural da época e da posteridade. A criança possui pensamento diferenciado do adulto e, por isso, precisa ser compreendida de maneira também diferenciada.

Piaget afirma que, embora exista um caminho possível, compartilhado pela espécie (sujeito universal), o desenvolvimento vai se atualizar em cada percurso (sujeito psicológico). Conforme o epistemólogo, os processos contínuos são organizados pelo sujeito epistêmico em estruturas graduais, com patamares diferenciados, que aparecerem em quatro estádios dinâmicos: o período sensório-motor (0 a 2 anos); o período pré-operatório (2 a 7 anos); o período de operações concretas (7 a 11 ou 12 anos); e o período de operações formais (11 ou 12 anos em diante).

O papel do professor de educação infantil é bastante significativo para o desenvolvimento da criança, pois ele é um observador ativo e, assim, também pode favorecer as interações que a criança estabelece em seu meio e a sua construção de conhecimento. Ao acompanhar e estimular a criança a construir noções iniciais de objeto permanente, espaço, tempo e causalidade, fundamentais para o seu desenvolvimento e a formação de novas estruturas cognitivas, o professor afeta, indiretamente, as futuras generalizações e interpretações em seu raciocínio lógico.

Volume 10 Número 2 - Ago-Dez/2018

www.marilia.unesp.br/scheme 


\section{Sthòme \\ Revista Eletrônica de Psicologia e Epistemologia Genéticas}

Estudo de caso: os relatos de rosa sobre as crianças

Para aprofundar a compreensão das relações teórico-práticas abordadas anteriormente, será apresentado um estudo de caso sobre o tema ${ }^{6}$. Piaget sempre trouxe em sua ideia o fazer e o compreender, ou seja, a teoria com a prática, mas ele só irá teorizar sobre, posteriormente. A bibliografia mostra as produções dos diferentes períodos da obra de Piaget, sendo que a questão específica do fazer e compreender vai ser usada pelo autor em período posterior, no quarto período de sua obra. Este, portanto, não é o foco do estudo.

A pesquisa não esgota contribuições sobre o tema, se observa as referências utilizadas dizem respeito aos períodos primeiro, segundo e terceiro e somente no quarto período com o estudo da Tomada de Consciência e o Fazer e Compreender, que Piaget vai aprofundar e vai teorizar sobre.

Rosa (pseudônimo) é uma professora de educação infantil sem formação superior completa que iniciou o curso de Pedagogia, mas o interrompeu no terceiro semestre. Aproveitou disciplinas do curso técnico de ensino médio para o de magistério e cursou as disciplinas específicas (as didáticas) que não tinham equivalência ao já concluído no curso técnico. Ela iniciou o trabalho com crianças após a conclusão do curso de magistério e trabalha em turno integral em uma escola privada da Grande Porto Alegre há mais de seis anos. Sua docência acontece em turma mista (crianças de colo a cinco anos de idade). $\mathrm{Na}$ entrevista, Rosa falou sobre as crianças de três a cinco anos, e os bebês, que ficaram aos cuidados de sua auxiliar, não foram mencionados. Rosa é mãe de adolescentes.

Como metodologia, utilizou-se uma entrevista semiestruturada que considera algumas contribuições inspiradas no método clínico de Jean Piaget.

6 Realizado como investigação preliminar de pesquisa de mestrado.

Volume 10 Número 2 - Ago-Dez/2018

www.marilia.unesp.br/scheme 


\section{Sthòme \\ Revista Eletrônica de Psicologia e Epistemologia Genéticas}

Segundo Delval (2002), nesse método, o entrevistador estabelece com o entrevistado certa interação a fim de deixá-lo o mais à vontade possível para expressar-se livremente, possibilitando sua atuação de acordo com o conteúdo que trouxer no momento, seja por meio de sua fala ou de suas ações. Nesse sentido, busca-se efetivar uma investigação com o objetivo de formular uma explicação acerca do que, no tema discutido, ainda não está claro.

Delval (2002, p.67) afirma que:

O método clínico é um procedimento para investigar [...] que procura descobrir o que não é evidente no que os sujeitos fazem ou dizem, o que está por trás da aparência de sua conduta, seja em ações ou palavras. Dado que muitas vezes o método clínico consiste em conversas com o sujeito, tende a ser identificado frequentemente como um método de entrevista verbal [...]

A contribuição do método clínico, neste caso, se refere à busca da compreensão do pensamento da entrevistada para além das respostas explícitas, à flexibilidade do roteiro da entrevista e ao uso de contra - argumentações.

A entrevista foi realizada fora do contexto escolar, em ambiente tranquilo e sem interrupções e teve a duração de 50 minutos. Foi gravada e transcrita pela mestranda. Foram seguidos os cuidados éticos previstos na Resolução $\mathrm{n} \square$ 510, de 07 de abril de 2016.

O procedimento é desenvolvido numa única etapa de entrevista, em que há contra-argumentos para os questionamentos efetuados. A entrevista foi transcrita e editada, da linguagem oral para a linguagem escrita convencional.

\section{A entrevista}

No decorrer da entrevista, Rosa pensa e articula informações de maneira organizada, demonstrando fundamentar-se em suas próprias experiências exitosas para construir suas respostas. As reticências usadas no texto de trans-

Volume 10 Número 2 - Ago-Dez/2018

www.marilia.unesp.br/scheme 


\section{Sthìme \\ Revista Eletrônica de Psicologia e Epistemologia Genéticas}

crição representam pausas ao falar, e os colchetes representam cortes na edição. Ao responder às perguntas, a entrevistada usa termos que remetem à teoria piagetiana, embora tenha afirmado não se lembrar da teoria e não guiar sua prática pelo prisma de qualquer teoria.

Para este estudo, foram selecionados, da transcrição completa da entrevista, todos os trechos que contribuem para a compreensão de como a professora relaciona a teoria e a prática no que se refere à mentalidade infantil. Dessa maneira, selecionou-se respostas significativas que ilustram o ponto de vista da entrevistada e que podem ser relacionadas com a teoria piagetiana. Os temas serão apresentados por tópicos. A investigadora é identificada por T, e a entrevistada, pelo pseudônimo Rosa. Os nomes das crianças citadas são fictícios.

\section{Análise dos resultados e comentários}

Para a investigação sobre a mentalidade infantil, serão comentados trechos de fala da entrevistada sobre os seguintes subtemas que abordou: 6.1.1) o colocar-se no lugar da criança para compreender sua ação e sua visão de mundo; 6.1.2) o simbolismo e a representação na criança; 6.1.3) o aprender a partir de jogos e brincadeiras; 6.1.4) as mudanças na socialização após a linguagem.

Colocar-se no lugar da criança para compreender sua ação e sua visão de mundo

Para Piaget, as relações vivenciadas pela criança durante seus primeiros anos de vida são essenciais para todo o seu processo construtivo e, portanto, é muito importante que suas singularidades sejam observadas e respeitadas.

Volume 10 Número 2 - Ago-Dez/2018

www.marilia.unesp.br/scheme 
“[...] tu vês que é uma criança que está se puxando e tu pões ela para a frente e incentiva. [...] é primordial esse acompanhamento que a gente faz. Tipo, o Vin (4 anos). Ele dizia: mas eu não consigo... - Tu consegues! Tenta! "

No trecho acima, Rosa parece entender que, como observadora ativa, poderá compreender melhor a criança, potencializando sua confiança em aprender. Segundo o autor, é muito importante que o adulto compreenda a forma como a criança se desenvolve e raciocina, como desenvolve suas ações e pensamentos. Se o professor de educação infantil compreender essas noções, favorecerá a aprendizagem da criança, isto é, o êxito reforçará sua autoestima.

“[...] para ser professora tem que amar, tem que gostar de sentar no chão mesmo [...]. É procurar ser como a criança."

A entrevistada coloca-se em uma postura semelhante à da criança, tentando compreendê-la em suas singularidades. Procurar ser como a criança implica estar consciente de que ela não pensa como o adulto e, dessa forma, tem sua própria maneira de agir para explorar seu ambiente.

“[...] é quando a criança está madura naquilo, ela passa para outro momento, mas ele não é igual no tempo da criança. Ele fica diferente! Ela consegue aprender mais."

“É a partir de tudo que trazem [...]. De tudo que eles já sabem, de muitas coisas. Ai, eles vão trazendo e vão ampliando essa vivência [...]"

Conforme Rosa, cada criança tem um tempo para aprender (ao usar o termo "maturação", a entrevistada não evidencia se acredita ser maturação biológica, caracterizando-se como inatista, ou se entende como uma construção interacionista). Ela parece acreditar que é das experiências prévias que resultarão as novas aprendizagens.

Volume 10 Número 2 - Ago-Dez/2018 www.marilia.unesp.br/scheme 
Pode-se considerar que há uma aproximação entre as observações de Rosa e a valorização dada por Piaget para as experiências práticas da criança. Por outro lado, deve-se destacar que o sentido dado ao termo maturação faz diferença. Na teoria de Piaget, maturação significa incluir a dimensão biológica nas interações com o real para que os processos de construção mental se desenvolvam e resultem na construção de esquemas e estruturas para aprender. Conforme se pode deduzir do que disse Rosa, mesmo sem intenção de teorizar ou ter consciência das relações de suas ideias com as explicações de Piaget, se a criança assimila, ela consegue aprender mais.

“Que nem o Vin. Ele não queria pintar, nem cortar, nem fazer nada! Ele não tinha interesse porque achava que não conseguia. E agora, ele anda para lá e para cá. [...] percebeu que consegue! Agora, ele está descobrindo o mundo, encantado com ele mesmo."

É possível compreender, de certa maneira, através desse comentário, o pensamento de Rosa sobre o tempo em que cada criança se desenvolve.

“T: - Dessa forma tu compreendes que cada criança se desenvolve de uma maneira que é diferente da outra?

Rosa: -- Sim, com certeza!“

Em conformidade com o que Rosa parece acreditar, a teoria piagetiana defende que essa compreensão é essencial, pois se a criança não estiver com sua estrutura cognitiva desenvolvida e pronta, não adianta provocá-la, porque ela não poderá assimilar a novidade e não irá aprender. Ela poderá, no máximo, memorizar, mas não vai descobrir por si mesma, as relações presentes na contextualização.

Volume 10 Número 2 - Ago-Dez/2018

www.marilia.unesp.br/scheme 


\section{Sthìme \\ Revista Eletrônica de Psicologia e Epistemologia Genéticas}

\section{Simbolismo e representação.}

A função simbólica com a imitação diferida, as brincadeiras de faz de conta e a linguagem apresentadas por Piaget (1964/2015) fazem parte do desenrolar dos processos contínuos e graduais do desenvolvimento da inteligência. No início do estádio pré-operatório, o pensamento não é mais dominado por fantasias e imaginações, mas por intuições. Esse estádio se caracteriza por apresentar um marco significativo para o desenvolvimento da criança, que é o aparecimento da função simbólica ou semiótica, sinalizando o início do pensamento intuitivo. Dessa forma, o jogo simbólico, a imagem mental e a linguagem da criança são diferentes manifestações da função simbólica.

Piaget (1964/2015, p. 68) afirma: “Estudando meus próprios filhos, compreendi melhor o papel da ação e, em especial, que as ações constituem o ponto de partida das futuras operações da inteligência". Ou seja, o autor defende que esse processo de desenvolvimento se desdobra desde o nascimento durante o período sensório-motor ( 0 a 2 anos) que se centra nas ações práticas, em suas transições e desenvolvimento através de representações e transformações cognitivas, que se caracterizam por sucessões graduadas destas modificações até a idade adulta, passando pelo período operatório concreto e o período formal.

“T: O que tu achas desse simbolismo e da representação que eles criam utilizando-se de objetos e coisas através do lúdico? Por exemplo: Com uma vassoura pensam um cavalinho... A boneca vira a filha, a mãe ou outra pessoa.

Rosa: [...] muito importante. Porque é a criatividade sendo posta em prática. A vivência e a bagagem que eles possuem de conhecimento. Eles vão trazendo, vão criando e criam uma linguagem nova, e criam esses sinais de linguagem [...]. Porque é muito séria essa brincadeira entre eles."

Volume 10 Número 2 - Ago-Dez/2018

www.marilia.unesp.br/scheme 
Rosa observa e valoriza as representações e simbolismos vivenciados pelas crianças nessa fase. Conforme Piaget, será através das brincadeiras, histórias criadas e faz de conta, de seus jogos imitativos e fantasiosos, dramáticos e representativos, que a criança simbolizará muito do que já assimilou anteriormente na prática, agora recriado por meio da imaginação (fantasia) e pela linguagem em sua mente.

"Num dia, bolei um cineminha! Numeramos as cadeirinhas, fizemos pipoca para vender. Como um combo da pipoca e ingresso... E usamos dinheirinhos do banco imobiliário. Tinha que ver, eles procurando a poltroninha... [...] olhando o número! Daí pegamos o pendrive e colocamos um filme. Foi muito legal. Eles adoraram!"

A entrevistada relembra uma atividade em que as crianças reviveram situações cotidianas através da dramatização (cineminha). Ela enfatiza o prazer das crianças e argumenta sobre a contribuição da atividade para o desenvolvimento cognitivo de seus alunos. Em sua fala, demonstrou a intenção de ensinar o número, mas não deixa claro como compreende a construção do número pela criança nem o porquê da escolha da atividade em seu planejamento e objetivos. E mesmo quando traz detalhes sobre a atividade, não diferencia o foco na quantidade ou nos símbolos numéricos.

“[...] eu dou o dinheirinho e tu (auxiliar) vais dar o troco e vender o ingresso. [...] aí, ela colocou dez reais (pipoca mais ingresso). E ficou estipulado. Só que para diversificar mais, uns tinham cem reais, outros tinham cinquenta, outros tinham dez... Para ver essa questão do troco, sabe? Fazer fila, ver a numeração e tal [...]. Foi tão rico! Eles procurando a poltroninha [...], olhando o número. Porque na nossa concepção de educadores, isso é construir conhecimento para ficar."

Volume 10 Número 2 - Ago-Dez/2018

www.marilia.unesp.br/scheme 
“T: - Aproveito essa tua fala e pergunto: Tu trabalhaste com eles os números? Como tu achas que eles desenvolvem essas noções de número nessa idade?

Rosa: - Repetindo... até aprender!"

Durante a entrevista, Rosa não esclarece como compreende a relação entre etapas de desenvolvimento e as noções que pretende trabalhar. Dessa forma, Rosa não deixa claro como trabalhar essas noções com as crianças, nem de como as compreende com relação às etapas de desenvolvimento. Dessa forma, Rosa demonstra a não compreensão dos tipos de conhecimentos trazidos por Piaget (1923/1993), ou seja, o conhecimento físico, o qual se obtém através da observação dos objetos na realidade externa, o conhecimento social, que depende da cultura em que se vive e o conhecimento lógico matemático, que resulta de conexões de ações e pensamento que o sujeito desenvolve com ou entre os objetos quando estiver agindo sobre eles. A partir do que Rosa disse, se deduz que ela trabalha com a repetição para que ocorra a aprendizagem do número. A entrevistada não demonstra compreender a diferença existente entre transformações reais e as aparentes, tampouco a importância desses processos para as compreensões e construções cognitivas das crianças, o que a impede de desenvolver um fazer com base científica.

“É no lúdico, quando estão brincando livremente, que tu vais descobrir, porque a criança é muito retraída, pois ela só vai mostrar [...] quando estiver livre e solta. E tem umas que se tu começas com jogos e fantasias, e começam a se expressar [...]. E assim, elas transmitem o que vivem brincando, como são os pais, como é a dinâmica da família[...], é brincando e fantasiando que ela se expressa."

É possível, através desse comentário, entender que Rosa compreende, de certa maneira, a importância das brincadeiras lúdicas, mesmo que não consiga defendê-la de forma teórica. O comentário remete ao que foi dito por

Volume 10 Número 2 - Ago-Dez/2018

www.marilia.unesp.br/scheme 
Piaget (1974/1978), que a criança traz para o plano de seu pensamento as ações já executadas - ou seja, no nível anterior, ela estruturou cognitivamente o mundo através da inteligência prática para, agora, fazê-lo no plano das representações.

“T: Tu achas que ela vai construindo [termo usado por Rosa anteriormente] mentalmente quando ela representa e simboliza? Quando ela faz essa construção?

Rosa: - Sim, ela faz essa construção mentalmente. Já está lá dentro, já está latente, vai só sair."

Embora a entrevistada tenha anteriormente usado o termo "construção", aqui Rosa utiliza expressões como "Já está lá dentro, já está latente, vai só sair." E não deixa claro, se está pensando em uma predisposição inata ou uma construção realizada durante o desenvolvimento cognitivo da criança. Dessa maneira, a maneira como Rosa se expressa não é suficiente para esclarecer se possui uma perspectiva inatista ou construtivista em relação desenvolvimento cognitivo.

Aprender a partir de jogos e brincadeiras

“T: Qual a importância do brincar livremente, para o desenvolvimento da criança? Como ela pode ser afetada pelos seus êxitos e fracassos?

Rosa: - Uns com outros, vão aprendendo a se conhecer, a conviver e a lidar com tudo. E a superar o que não gosta. Porque ali, eles vão aprendendo. E essas brincadeiras naturais realizadas pela criança em que ela conversa com ela mesma e com outras, são muito importantes."

Nessa fala de Rosa, é possível perceber sua compreensão sobre o convívio entre as crianças nas brincadeiras que potencializam o desenvolvimento de suas funções cognitivas. Isso vai ao encontro do que Piaget traz em sua

Volume 10 Número 2 - Ago-Dez/2018

www.marilia.unesp.br/scheme 


\section{Sthòme \\ Revista Eletrônica de Psicologia e Epistemologia Genéticas}

teoria (Piaget, 1974/1978). Porém, Rosa não deixa clara sua compreensão da influência do ato de brincar no desenvolvimento da criança quanto às transformações cognitivas relacionadas ao real e ao aparente. Ela demonstra, de certa forma, uma compreensão mais geral de que a brincadeira é indispensável para toda formação infantil e argumenta sobre a importância da brincadeira para ajudar a desenvolver nas crianças a criatividade, a curiosidade, a linguagem, etc., dizendo ser essa a função da educação infantil.

“T: - Tu aproveitaste a situação e trabalhaste a inclusão?

Rosa: - Isso! E o que pegou a bonequinha sem braço, amou! Ele o tempo todo cuidando [...]. Davam papinha, trocaram fralda, levaram para passear. Foi muito rico! [...] porque a criança quando brinca, ela está reproduzindo. [...] é para isso que é a educação infantil. [...]. Ela ser mais criativa. Mais curiosa!"

Nesse episódio com a boneca sem braço, Rosa parece se aproveitar do acaso para trabalhar a inclusão (um tema atual que se tornou parte do cotidiano nas escolas com as novas leis educacionais), porém demonstra dificuldades para a reflexão teórica ou aprofundada sobre a importância dessa representação e desse simbolismo para desenvolver qualquer atividade lúdica proposta com objetivos definidos. No relato da brincadeira, parece que o tema inicialmente não era significativo e que foi a reação do aluno que a interessou. Assim, Rosa também demonstra certa flexibilidade no que propõe a ser trabalhado com as crianças. Ela parece se colocar na perspectiva das crianças para desenvolver seu trabalho; porém, os temas desenvolvidos, no caso o instinto paternal e maternal, deflagram as brincadeiras, mas não são desenvolvidos com uma intenção pedagógica específica ou um planejamento anterior. De certa forma, Rosa dá a entender que o tema inclusão não era significativo para aprendizagem até aparecer a situação da boneca sem o braço, quando, intuitivamente, ela resolveu

Volume 10 Número 2 - Ago-Dez/2018

www.marilia.unesp.br/scheme 
trabalhá-lo. Como ficou explícito na reação e conduta positiva do menino em relação à boneca, Rosa demonstra ter percebido o quanto a atividade foi proveitosa e rica, parecendo relacionar o que trabalhou com a inclusão.

A brincadeira desenvolvida teve mostras de interesses e prazer nas crianças, demonstrando êxito na atividade lúdica, do qual Rosa tira suas explicações. A aceitação do brinquedo por parte da criança, ou sua significação do tema, foi destacada para ilustrar o êxito da atividade. Piaget afirma que os jogos e as brincadeiras tornam-se significativos a partir do interesse demonstrado pela criança, sendo muito importantes quando, a partir da imitação e da ficção, ela passa a reconstituir, reinventar coisas e eventos, o que lhe exige uma adaptação e estruturação mental bem elaborada.

"O que eles vivem, eles trazem para a sala de aula. E é nas brincadeiras que a gente vai conhecendo. $E$, às vezes, tu não consegues entender aquele mundo da fantasia. Mas eles entre si, se entendem! É como se estivessem num mundinho a parte! "

Rosa demonstra certa dificuldade de compreender as falas e interpretações das crianças durante seus momentos lúdicos de representações e fantasias. Em outras falas, relaciona as dramatizações e simbolismos a vivências das crianças em família. Ela parece considerar o jogo como uma reprodução de experiências, e não faz relações com teorias para interpretar seu significado cognitivo ou afetivo.

Rosa também relaciona, de forma não proposital, o que Piaget traz em sua teoria sobre a dificuldade que o adulto possui ao tentar compreender uma criança. Conforme o autor, essa dificuldade reside no fato de que o ponto de vista do observador é diferente do ponto de vista da criança. Quanto mais o sujeito conseguir se descentrar, mais reduzirá seu egocentrismo, podendo, as- 


\section{Sthìme \\ Revista Eletrônica de Psicologia e Epistemologia Genéticas}

sim, compreender o ponto de vista de seus pares, o que deverá ocorrer em estádios posteriores de desenvolvimento. Muitas vezes, conforme Rosa, ela sabe se a atividade valeu a pena conforme as crianças demonstram terem gostado ou não.

“Fizemos uma atividade sobre alimentação saudável. [...] construímos um caderninho que ia para casa e lá registravam tudo. Podia ser com fotos, desenhos, colagens, etc. [...] depois chegavam na sala e contavam tudo para os outros. [...]. No final do projeto, a culminância foi uma ida ao mercado, para comprarmos produtos e fazermos um sanduíche saudável para cada um. Eles gostaram muito!"

No comentário acima, Rosa conclui seu resultado de êxito por meio do interesse demonstrado pelas crianças. Ela menciona uma atividade previamente planejada e acompanhada, mas não traz maiores detalhes sobre as compreensões cognitivas das crianças e demonstra valorizar certa dimensão de valores positivos somente através das reações obtidas pelas mesmas. Não há uma reflexão sobre as aprendizagens, os objetivos alcançados, as histórias ocorridas com as crianças, mesmo descrevendo várias atividades realizadas durante certo tempo nesse projeto.

Ainda assim, Rosa demonstra ter compreensão de que, durante seu tempo com as crianças, algo acontece entre elas nas brincadeiras, pois afirmou que os alunos aprendem uns com os outros e se entendem, conforme suas necessidades, durante as brincadeiras e fantasias, demonstrando suas experiências mediante imitações e interpretações.

“Tu sabes que até as próprias crianças[...] acham que aquilo que não é pintar, escrever, é só brincadeira, não vale como aprendizagem. E como tem essa concepção errônea! Às vezes, faço teatrinho e eles perguntam das atividades. Me decepciono! Pois acho importante, porque afinal a cri-

Volume 10 Número 2 - Ago-Dez/2018

www.marilia.unesp.br/scheme 


\section{Sihème \\ Revista Eletrônica de Psicologia e Epistemologia Genéticas}

ança está descobrindo, está conhecendo outras linguagens, outras coisas[...]"

Rosa parece se utilizar do brincar como importante meio para despertar nas crianças certas aprendizagens. Demonstra compreensão de que, brincando, a criança desenvolve seu pensar, dando-lhe significados verbais. A entrevistada deixa claro que são seus êxitos e fracassos que dão sentido ao que observa e utiliza-se dessas observações para a proposição de outras atividades.

\section{Mudanças na socialização após a linguagem}

A criança passa por grandes mudanças durante a aquisição da linguagem, pois, com ela, seu desenvolvimento social se acelera. Gradualmente, a criança começa a atribuir sentido a tudo o que escuta e a sua linguagem verbal. Para Piaget (1923/1993), quanto mais relações e interações a criança estabelecer com o meio externo e com as pessoas, mais relações de significância conseguirá realizar mentalmente.

"Antes de sair a fala [...] se comunica através dos sinais, gritinhos e sorrisos. Depois começa a balbuciar[...], mas a comunicação, ela vem antes. Pois o bebê, se comunica pelo sorriso e pelas brincadeiras. [...] e nisso tem mudança, porque vai sendo aprimorado. Cada vez mais! Porque uma coisa vai puxando a outra. [...] começa com a comunicação pelo olhar, através de sinais, de símbolos. Vai tendo uma comunicação até a fala. [...] vai construindo, aprimorando, melhorando até conseguir falar bem. Porque eles conversam entre si e inventam histórias. E vão criando."

Rosa dá sentido ao que observa, mesmo sem desenvolver teoria.

Com suas crenças e convicções, tenta comunicar algo que dá sentido e significado ao que ela vê nas representações e interpretações e ao que ouve nas falas das crianças e nas suas comunicações com elas. A entrevistada não relaciona

Volume 10 Número 2 - Ago-Dez/2018

www.marilia.unesp.br/scheme 


\section{Sthòme \\ Revista Eletrônica de Psicologia e Epistemologia Genéticas}

suas observações com quantidade do discurso verbalizado que as crianças possuem, mas faz algumas referências qualitativas sobre a comunicação verbal entre elas. Ao referir-se às falas das crianças, em nenhum momento lembrou de descrever características próprias, de histórias vividas pelas crianças, relacionadas ao animismo, ao realismo, ao artificialismo ou finalismo, com exceção de algumas referências ao egocentrismo.

“[...] no convívio com os outros, vai ser tratado. Essa questão do egoísmo. [...] de se colocar no lugar do outro."

A partir da fala anterior, Rosa parece demonstrar compreender egocentrismo de forma equivocada, como ocorreu com alguns teóricos logo que Piaget o utilizou. Este conceito foi inicialmente compreendido como relacionado às emoções, e não à cognição. Para Piaget, a criança, em seu processo de construção mental, deforma a realidade em função de seu próprio ponto de vista. Não percebe o todo, focalizando somente certa propriedade e ignorando outras por dificuldade para coordená-las entre si. Esse é um processo intelectual, cognitivo, e não emocional. Os comentários realizados por Rosa confundem egocentrismo com egoísmo.

“[...] teatrinho é uma atividade maravilhosa. Eles falam cada coisa, ficam conversando e parece que um não entende nada que o outro diz, mas responde."

$\mathrm{Na}$ fala acima, Rosa não teoriza conscientemente, mas, de forma bastante simples, afirma que é possível dividir todas as frases das falas das crianças em dois grandes grupos, que, na teoria piagetiana, são chamados de egocêntrico e socializado. (PIAGET, 1923/1993, p. 7). Conforme Piaget, a criança do primeiro grupo traz características próprias ao falar, como a falta de preocupação em saber com quem fala ou se alguém a escuta. Ela não fala nada que não se refira a si mesma e, por vezes, demonstra a ilusão de ser ouvida e compreendida (exce-

Volume 10 Número 2 - Ago-Dez/2018 www.marilia.unesp.br/scheme 


\section{Sthòme \\ Revista Eletrônica de Psicologia e Epistemologia Genéticas}

to no monólogo puro), mas não tem a necessidade de ter um interlocutor. Para o autor, será um monólogo coletivo quando a criança fala de si sem se preocupar com o ponto de vista do outro ou se está sendo ouvida. O interlocutor nunca intervém.

Rosa também traz uma fala, mesmo sem se referir à idade da criança, que deixa transparecer a necessidade desta de ser ouvida e compreendida e de receber uma resposta. Conforme o autor, é quando a criança consegue se colocar no ponto de vista do interlocutor que a linguagem passa a ser socializada.

“[...] é ali que ela vai aprender a ver o outro. Muitas vezes, é rejeitada! [...] E vão e procuram ajuda para serem aceitos."

Como Rosa descreve, a ação se torna fonte de brigas e rivalidades. As ordens, súplicas e ameaças ocorrem quando há a ação de uma criança sobre a outra. As perguntas, que são perguntas de crianças para crianças, exigem respostas, e há respostas que são outras perguntas: a fase dos porquês.

“Eu e a Clarinha (3 anos), perguntei se ela me amava? Ela respondeu que só um pouquinho. Aí eu perguntei: Por que só um pouquinho? E ela disse: - Porque se amar demais, vai derramar. Olha só, o que ela pensou [...]"

Conforme a entrevistada, a criança coloca em palavras o que já estava interiorizado nela e sendo construído mentalmente. Rosa parece não conseguir esclarecer o que quer dizer com construção interiorizada nem compreender a forma indiferenciada que a criança estabelece em seu pensamento ou a riqueza de linguagem utilizada. Ela explora muitas ideias, as quais acredita que contribuem para o desenvolvimento das crianças, porém não consegue explicar se acredita que o potencial desenvolvido já está na criança ou se ela o constrói em sua relação com o meio. Aqui também se mantém a dúvida sobre qual perspec-

Volume 10 Número 2 - Ago-Dez/2018

www.marilia.unesp.br/scheme 
tiva Rosa evidencia mais em suas verbalizações e ações com as crianças, se é a inatista ou a interacionista. Entende-se que há uma mescla de informações e assimilações provenientes de ambas.

\section{Conclusão}

Com base no que foi descrito, conclui-se que esse estudo responde parcialmente à questão de pesquisa, na medida em que, mesmo sem ter completado a qualificação acadêmica específica na área de desenvolvimento infantil, Rosa observa, por meio da prática, os êxitos e os fracassos das atividades desenvolvidas com as crianças. Dessa maneira, em seu acompanhamento docente ativo e flexível, ela é capaz de promover situações de aprendizagem significativas para a etapa do desenvolvimento que abordou.

A observação de Rosa, portanto, resulta em um trabalho exitoso para com as crianças; o que também se demonstra pelo fato de que a educadora permanece aberta aos mais distintos aprendizados que ela mesma pode ter enquanto docente. Contudo, deve-se atentar ao fato de que, mesmo sendo capaz de preconizar questões relevantes no que tange à mentalidade infantil, percebese, por vezes, que; em seus comentários, ela não compreende os aspectos desse desenvolvimento próprio. A este fim se deve a teoria Piagetiana: basear e dar fundamento pedagógico de forma a compreender aquilo que faz e por que faz. Dessa maneira, estará transcendendo a prática empirista, intuitiva, por meio de abstrações reflexionantes, passando assim da ação para a operação.

Na análise realizada, foi possível estabelecer relações entre as afirmações de Rosa e a conceitualização da mentalidade infantil, de acordo com as características citadas anteriormente neste texto, com base na teoria piagetiana. 
De forma complementar, as relações e deduções realizadas pela pesquisadora, em sua análise dos trechos de fala, destacam como essa docente de educação infantil sem formação superior ou específica completa interpreta as condutas infantis e como alcança algumas aproximações com os achados da teoria piagetiana, mesmo sem a conhecer.

Reafirma-se que a conduta observável das crianças, durante seu desenvolvimento, seja como sujeito psicológico, seja como sujeito epistêmico, possibilita a construção de competências docentes à medida que os profissionais percebem, a partir de observações e de reflexões aguçadas, que as crianças possuem características universais e individuais. Esse professor passa, portanto, a desenvolver as práticas e o próprio planejamento de atividades baseando-se nas observações ativas e experiências profissionais exitosas.

Pode-se, ainda, questionar se elementos da teoria piagetiana se expressam de maneira inconsciente nesses profissionais por estarem já difundidos na cultura educacional institucionalizada ou se é o próprio convívio com as crianças que ensina para a docente o que é relevante para elas. Os indicadores da mentalidade infantil apareceram de forma empírica neste estudo de caso, mas corroboram a hipótese de que uma observação ativa e reflexões a respeito do que as crianças vivenciam e verbalizam potencializam a aprendizagem do professor.

Em suas falas, Rosa demonstra, inúmeras vezes, compreensões que a aproximam de uma perspectiva inatista. Contudo, a professora contraria essa ideia ao fazer comentários sobre construções que as crianças fazem ao se desenvolverem, com as quais utiliza novas formas de desenvolver as atividades, valorizando as mudanças nas condutas dos alunos.

Volume 10 Número 2 - Ago-Dez/2018

www.marilia.unesp.br/scheme 


\section{Sthòme \\ Revista Eletrônica de Psicologia e Epistemologia Genéticas}

Outro aspecto relevante na prática de Rosa em educação infantil é o fato de que, quando a criança tenta adivinhar as respostas, ela considera que há diversas possibilidades. Essa informação é extremamente rica para um professor que procura descentrar-se a fim de se colocar no lugar da criança e compreendê-la. Isso expressa a compreensão de que, para o professor, esse processo exige olhar para a criança como Piaget o fez, ou seja, como alguém que raciocina de maneira diferenciada do adulto.

A experiência que o professor adquire permite refletir sobre como se compõem os diversos encaixes mentais dessas crianças, abarcando suas complementaridades relativas, suas afirmações, suas negações parciais, etc. (PIAGET; INHELDER, 1966/1993). Se a criança demonstra a capacidade de compreensão da natureza transitiva da ação de cada elemento sobre os demais, se inferirá com isso o seu nível de descentração. Por conseguinte, o professor compreenderá quando a criança possui uma ideia parcial, e não total, do que ocorre. Ele entenderá, desse modo, que a criança compreende até um determinado ponto.

Sob o que já foi exposto, compreende-se que cada professor traz sua própria construção individual, iniciada desde seu período sensório-motor no contexto familiar e ampliada pela escolarização. Isto é, cada docente é muito do que constrói ao longo de sua trajetória e caminhada acadêmica, delineando, assim, um fazer próprio através dos estádios universais. Ele faz escolhas e estudos ao assimilar conhecimentos em suas formações e cursos. Defende-se, pois, nesse estudo de caso, que a reflexão própria tem primazia sobre as teorias recebidas como prontas e as práticas repetidas ou imitadas.

A relação estabelecida no curso e a possibilidade de que o professor em formação coordene diferentes perspectivas teóricas apresentadas nos cursos

Volume 10 Número 2 - Ago-Dez/2018

www.marilia.unesp.br/scheme 
podem colaborar para reflexões que lhes permitam chegar a uma explicação teórica, de sistematização/generalização do próprio ponto de vista, e recriar a teoria.

\section{Referências}

BRASIL. Lei $\mathrm{n}^{\mathrm{o}} 11.114$, de 16 de maio de 2005. Altera os arts. 6o, 30, 32 e 87 da Lei no 9.394, de 20 de dezembro de 1996, com o objetivo de tornar obrigatório o início do ensino fundamental aos seis anos de idade. Disponível em: <http://www.planalto.gov.br/ccivil_03/_ato2004-2006/2005/lei/111114.htm>. Acesso em 28 ago. 2018.

. Ministério da Saúde, Conselho Nacional de Saúde. Resolução $n^{\circ}$ 5110, de 07 de abril de 2016. Diário Oficial da União, Brasília, DF, n. 98, p; 44-46, 24 maio 2017. Seção 1

CLAPARÈDE. E. [1923] Prefácio. In: PIAGET, Jean. A Linguagem e o Pensamento da Criança. 6. ed. São Paulo: Martins Fontes 1993. P. IX-XIV. Tradução de Manuel Campos; revisão da tradução e texto final: Marina Appenzeller e Áurea Regina Sartori.

DELVAL, Juan. Introdução a pratica do método Clínico: descobrindo o pensamento das crianças. Porto Alegre: Artmed, 2002.

DONGO MONTOYA, A. O. et al. (orgs.) Jean Piaget no século XXI: escritos de epistemologia e psicologia genéticas. São Paulo: Cultura Acadêmica; Rosaília: Oficina Universitária, 2011.

MONTANGERO, J.; MAURICE-NAVILLE, D. Piaget ou a inteligência em evolução. Porto Alegre: Artmed, 1998. Tradução Fernando Becker e Tânia Beatriz Iwaszko.

PIAGET, J. [1945]. A formação do símbolo na criança. Imitação, jogo e sonho, imagem e representação. Rio de Janeiro: Editora LTC, 1978. Traduzido por Editions Delachax et Niestlé.

Volume 10 Número 2 - Ago-Dez/2018

www.marilia.unesp.br/scheme 
Jean [1974]. Fazer e Compreender. Trad. Cristina L. de P. Leite. São Paulo: Melhoramentos; EDUSP, 1978. Tradução de Christina Larroudé de Paula Leite; revisão técnica de Lysandre Maria Castelo Branco.

Jean [1967]. Biologia e Conhecimento. 2. ed. Petrópolis: Vozes,1996. Traduções de Nathanael C. Caixeiro, Zilda A. Daeir, Celia E.A. Di Pietro.

Jean [1923]. A Linguagem e o Pensamento da Criança. 6. ed. São Paulo: Martins Fontes 1993. Tradução de Manuel Campos; revisão da tradução e texto final: Marina Appenzeller e Áurea Regina Sartori.

Jean [1964]. Seis Estudos de Psicologia. 25. ed. Rio de Janeiro: Forense Universitária, 2015. Tradução Maria Alice Magalhães D’ Amorim e Paulo Sérgio Lima e Silva.

Jean. [1949] A pedagogia moderna. In: PIAGET, Jean. Sobre a Pedagogia: textos inéditos. São Paulo: Casa do Psicólogo, 1998. P. 181-185.

Jean [1926]. A representação do mundo na criança. Rio de Janeiro: Fundo de Cultura, [s.d.]. Tradução Adail Ubirajara Sobral (colaboração de Maria Stela Gonçalves.

Jean [1966]. INHELDER, B. A psicologia da criança. Rio de Janeiro: Bertrand Brasil, 1993. Tradução de Octavio Mendes Cajado,1998. Tradução.

Recebido em: 30/08/2018

Aprovado em: 05/11/2018

Volume 10 Número 2 - Ago-Dez/2018

www.marilia.unesp.br/scheme 